\title{
Sustainable Fashion Education in changing World Scenario
}

\author{
Vishaka Agarwal ${ }^{1}$
}

\begin{abstract}
With the changing world scenario, information technology is hitting all walks of life, the globalised phenomenon along with alarming environmental concerns have led the world to innovate ways and methods to address various concerns in a sustainable way. Fashion education also needs to undergo change in its pedagogy and develop newer knowledge source and materials which are eco-friendly , leaving less carbon footprints on the earth .The fashion Education curriculum needs to have more "Free Thinking" orientation and interaction and information of technological advances of materials and processes which consume less energy and less waste post production. Looking at current trends, the future would require Fashion Designers to have multidisciplinary knowledge of Design, Technology and managerial skills to evolve and compete in the Fashion Industry. Questionnaire would be made to collect the perception from Fashion experts, professionals, Academia and students to assess the kind of knowledge they would like to be incorporated in the Fashion curriculum which has sustainable concepts incorporated in keeping tandem with the future trends.
\end{abstract}

Keywords: Fashion, Curricula, Sustainable, Education

\section{Introduction}

Fashion today has become a most dynamic aspect in the world hitting all walks of life. And all the strata of society. We find fashion involved in everything we see around in terms of Colour, shape forms and material. As fashion has pervaded all economic and social strata of society across the world, so this gives challenge to the designers to produce and think of ideas which are economical and which addresses environmental concerns. Thereby making Fashion Education accessible to all interested and having the design skills so that these can be further developed into design creativity to create new ideas which are environment friendly.

Teaching pedagogy has to come out from the walls of classroom and give space and time to the 'New Thinker' to think about new ideas in the way the brain his / her brain can think of. This requires the Fashion curriculum to be more diverse and open to allow the 'New Thinker 'to come up with ideas and solution which are sustainable and economical. They should be given time and space to explore on ideas in an liberalised environment .As the New Learner is technology and social media savvy they have a wider exchange platform to share and develop ideas. International Technology and design exchange should be promoted by institutes so as to expose the new learner to the latest updated technological advances so that they are able to create new ideas which are competitive on world platform and are able to do frugal innovation by consuming less resource and produce more. 


\section{The Teacher as Designer}

The main aim of Education is to provide knowledge to the society. Traditional methods of education which involved classroom teaching and assignments is not what the generation today require. Activated sensibilities towards creative innovation to solve ambiguity and complexity are now the main focus of learner's todays. Kalatinzis and Cope (2010) states that the todays learner do not want to be just passive listeners of the textbook knowledge. They want to be participative, innovators, risk takers creative learner who want to give solution to problems.

The curriculum should motivate them to actively engage them in real life practical challenges. The New Learners is ready to take greater responsibility for their learning if they are given autonomy and self-control. They will become knowledge producers and resource instead of only being consumers who will read the just the book .They would work effectively in groups beyond classroom and use the social media and e media to learn anytime and anywhere. The New Learner as well as the 'New Teacher' has to change. The New Teacher has to deliver knowledge authoritatively without being authoritarian. The New Teachers needs to be liberal and needs to assess the students as they are progressing even if they are not on the same page at one time. It is a continuous assessment which the new teacher has to do depending on the learning level and need of the student. So the new student needs more ' free thinking " mode of curriculum deliverance and knowledge in a free environment where they are left free to think and find solution to their creative thought process.

\section{Current Design Curriculum}

The Fashion Design curriculum delivered around the world involves a Foundation year of curriculum in which design fundamentals are delivered. Then the students enter the core program of 3 years. In the core program emphasis is on imparting technical skills and knowledge of different types fabrics, surface embellishment, pattern making and garment construction techniques along with knowing fashion forecast and different markets. Also the curriculum delves in marketing and display techniques to enhance sell. Along with this theoretical and practical deliverance, there are visit to the industry to enable students to know the current industry and working procedure. Also experts from industry are invited to share their experience and requirement of the industry.

In India at the National Institute of Fashion Technology, in order to have the future designers be connected to their country craft and culture they are sent to craft clusters to interact with the artisans and understand how they make the products using different techniques.

Computer aided designing using updated latest software are part of the curriculum in each semester so that students can use e media to design and give various effects to design at a faster and easy way.

Semester Abroad Exchange Programs are also floated to allow the students to have international exposure to design and learn about the design concept happening internationally. The aim of this undergraduate design curriculum to prepare the graduates 
for the industry some of whom enter the industry immediately after the graduation as assistant designers and some look ahead to some higher studies to management and design programs to enhance their skills.

Faerm(2012) refers to Marshall (2009) states the German state school 'The Bauhaus' (1919-1933) had strongly influenced the primary structure of the American art and design education. He further states that many fashion design programs of America duplicated the Bauhaus education format of 'learning by doing '.The students learnt various design fundamentals in the foundation year before choosing their specialisation. Faerm(2012) states that many American design schools like the Parson school of design had their academic curriculum similar to the Bahaus, based on vocational industry oriented approach(Wolff\& Rhee,2009). The other Fashion Design Institute 'Fashion Institute of technology' was launched by government support to supply the apparel industry with qualified labour.today the fashion design curriculum aims to develop practical skills and creative sensibilities so that they may cater to industry needs.

\section{Current Industry Requirement}

Environmental concerns are today the most important area where the entire world is thinking and focusing on. Industry is demanding better eco - friendly solutions therefore designers have to look for better alternatives to the product processing and raw material sources. These new breed of designers would be the 'vehicles of change' in the industry for which the educator's and the curriculum has to be updated accordingly.

Faerm (2012) quotes “.........to foster a new generation of designer citizens: productive, engaged, inventive businesspeople, policy makers, and community activist, many of whom also make beautiful and useful thing" (Wolf \& Rhee , 2011).

Academicians have to think of how to make these new designers suitable to the shifting professional scenario? How they can prepare the graduates to be suitable for the all the varied kind of opportunities and challenges lying in the professional world.

\section{The New Education Curriculum}

As fashion is globalised phenomenon hence it has a very unpredictable future. As fashion caters to different economy, culture, societal values of the world therefore the fashion designers require to know the nuances of the different culture and societies of the world along with the evolving technological innovation and new resources which are being identified for the sustainable future. The fashion curricula needs to prepare the curriculum which is interdisciplinary and transdisciplinary which would prepare graduates to develop capability to synthesize with other discipline and technology to innovate new products. Faerm (2012)quotes Joel Towers, Dean of Parsons school of Design that there are moments when narrowness of academic studies makes sense when specific expertise is necessary but today the issues that we have to address and their complexity require a breadth of knowledge. Faerm states that Parsons the New School of Design has created a transdisciplinary Design in which students from diverse fields work as design team.

As design has pervaded in all the products that we see and use along with the 
environmental concerns hitting the world deeply, therefore designers have a key role to play to attend to this issue. 'Frugal innovation' is a solution to this contemporary needs which aims to ' produce more from less resource'. The curricula need to be designed with this concept of Frugal innovation so that the future designers are able to create and innovate new products.

Wahl and Baxter (2008) mentions that Sustainability requires widespread participation of communities worldwide at local, regional and across international borders to achieve the vision into reality. Therefore, in order to achieve universal acceptable design which is sustainable, we need to develop a system in which everyone participates and is a member in its creation and is ready to adapt the socio-cultural processes of change. Such a process of Trans disciplinary and integrative design process will have holistic solution that promotes sustainability across different culture and economies of the world meeting the needs, values, attitudes and desires.

Wahl and Baxter (2008) states that Design is the core element of all human needs and designers should have the potential to act as trans disciplinary correlational and coordinating agent. Designers can act as facilitators in integration of the various trans disciplinary attributes.

Venkataraman(2009) states that in 2002 at the World Summit on Sustainable Development, the conference emphasized the need for the concern and linking education with sustainable development. The decade 2004-2015 was declared as the 'Decade of Education for Sustainable Development' (DESD) by the United Nations General Assembly in 2002.The main aim behind 'Education for Sustainable Development is to involve education in the development of the society with the core essence of sustainable development.

Design institutions and faculties should design curriculum which should have Cross breeding of design, science, business and technology to innovate products for our society which is driven by social media, technology and environmental concerns. Wahl and Baxter (2008) states that Design is the core element of all human needs and designers should have the potential to act as trans disciplinary correlational and co-ordinating agent. Designers can act as facilitators in integration of the various trans disciplinary attributes.

Wilber (2001) states that a framework is required to consolidate the understanding for acknowledging and co-relating different perspective and worldviews. The need of the hour is to determine the ideal balance in curriculum of conceptual education including research and experimentation with practical application to prepare the grounds for students to nurture originality and creativity..

Faerm(2012) refers to Joel Towers who states that students must acquire the skills that will help them sustain in the current market as well as train them to improve and upgrade the future industry. The paradigm shift therefore thinks over making in design education. Industry must define 'design expert' attributes as that will help the academia to develop the Curriculum accordingly which will satisfy the future needs of the industry.

\section{The Attributes of the Emerging Generation}

The redesigning of the fashion curriculum also requires looking into and 
understanding the psychology of the future design student. What do these students like and how they perceive future?

Today's youth is exposed diversity in culture, religion and ethnicity which the young adults face in academics and community. These youth have to learn to survive in the integrated environment even if their parents were not exposed to such experience.

In this age group of 19-23 years, Youth have to come out from the protected environment of the parents, change from a 'taker' to a 'self-reliant' person and adopt a realistic lifestyle and become more responsible. This kind of change from a dependent person to completely independent person may be difficult for new fashion designers as this field is highly competitive with limited job vacancies. For making a niche in the society is an advantage available to only few who are at the top of class.

\section{Results}

A field survey was conducted with a structured questionnaire of closed ended question among Academicians, Professional and students of sample size 60 respondents. The students size was 40 and professional and academician size were 10 each. The results received from the field survey is detailed below.

i) Theory and process based subjects: From the response, 'Academicians ' suggested that the theory subjects should be reduced to $20 \%$ and $80 \%$ process based subjects should be given weightage.'Students' feel that there should be only $15 \%$ of theory subjects and $85 \%$ should be process based while 'Professionals' feels that there should be only $10 \%$ theory based subjects while $\mathbf{9 0 \%}$ feel that more of practical subjects should be there in curriculum (Fig.1).

Fig 1 .

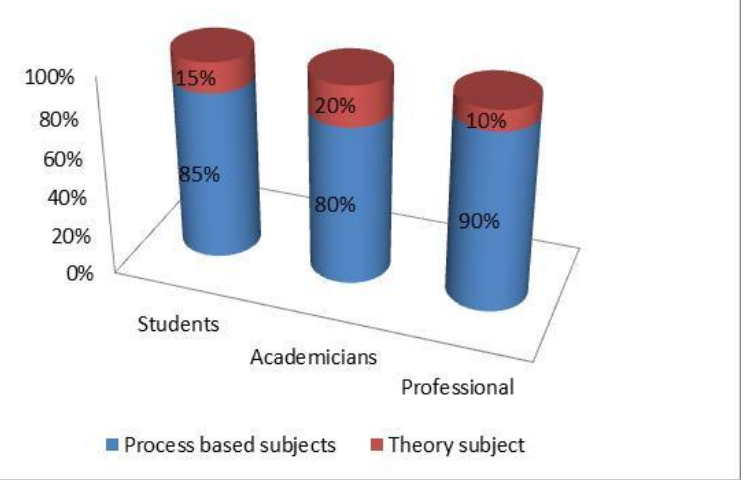

ii) Classroom, Field visit and interaction with faculty: $45 \%$ of the respondents suggested that the Classroom hours should be reduced and more field research and personal interaction with faculties should be promoted so that the students can discuss their ideas on one to one basis with the faculties as this is a creative field and there are more chances of ideas being swapped by others if discussed openly. Field vsit would give them more update practice knowledge of the industry.(Fig.2) 


\section{\% Distribution of Semester Hours}

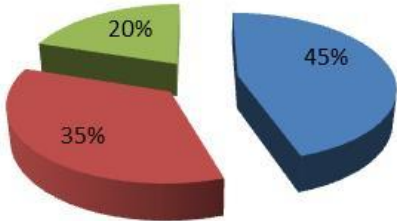

- Classroom hours

a Field visit

= Interaction with faculty

Fig. 2

iii) Assignment Type: 87\% of the respondents were of the views that the subject assignments should be open in the area of topic so that students can exercise creativity within the scope of the subject under close reviews by the subject faculty to have a creative output.(Fig3)

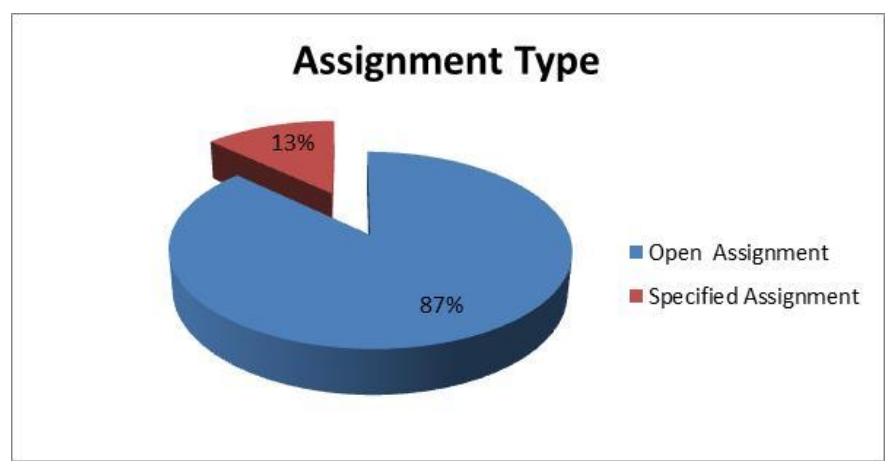

Fig.3

iv) Sustainable Concepts: $85 \%$ of the respondents are interested in the concept of sustainability while $10 \%$ are not clear as to how to implement the concept of sustainability in design process. Rest $5 \%$ are not quite aware of the sustainability factors.(Fig.4)

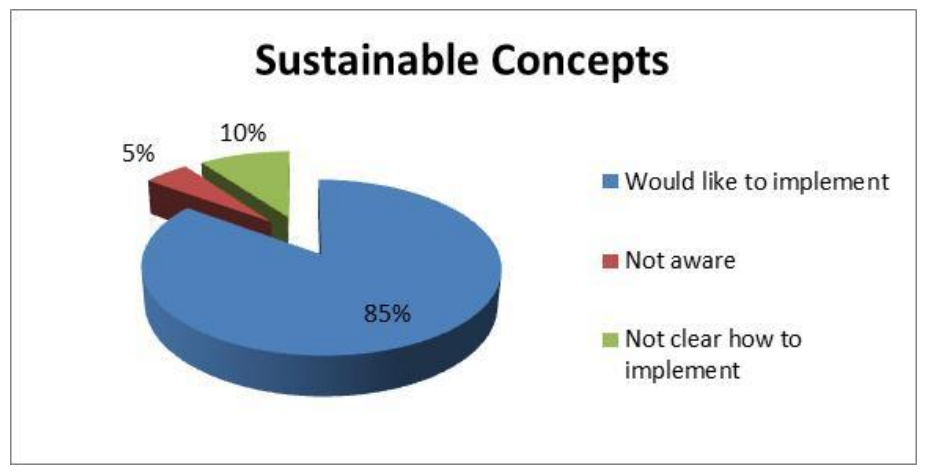

Fig.4 
v) Free Thinking: 40\% respondents 'agree' that Practical Classes and field visits hours should be increased so that more practical understanding can be attained as professionals. $25 \%$ ' agree' that more of field visit to design houses, fairs and industry should be emphasized only while 35\% agree that more practical classes should be conducted.(Fig5)

\section{Free Thinking}
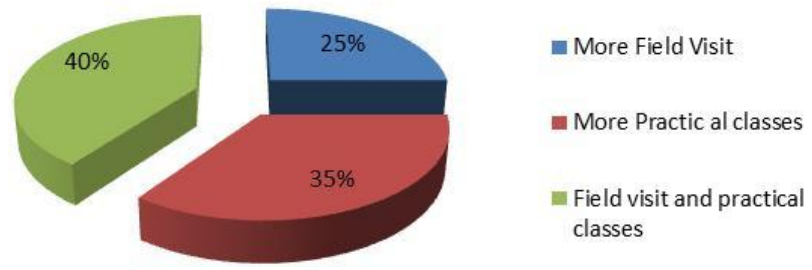

Fig.5

vi) Communication Technology: 65\% respondents feel that more of Communication technology should be introduced so that virtual classes may be conducted where they can attend classes through skype fro national and international exposure. $30 \%$ 'do not agree " that virtual classes would be beneficial while 5\% 'partially agree " that virtual classes would be helpful in design creation .(Fig.6)

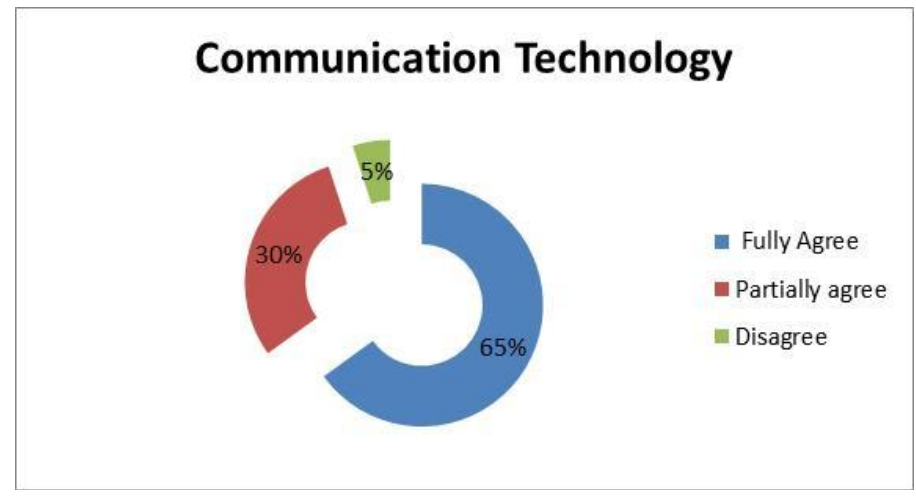

Fig.6

vii) International Exchange program: 60\% respondents 'agree' international experts exchange will help in developing professional who are able to meet the challenges of the profession in a globalised manner and serve the society in better way.35\% "partially agree " that Exchange programs would be more beneficial where students spent a semester in international university. 5\% disagree with both.(Fig.7) 


\section{International Exchange Program}

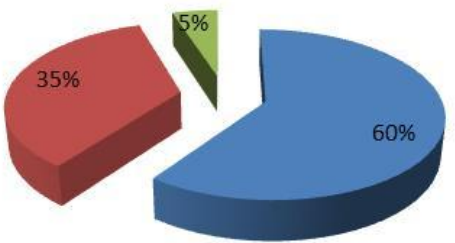

- Fully Agree

- Partially Agree

Disagree

Fig.7

viii) Student Faculty ratio: $85 \%$ of the respondents 'fully agree' that Design institutions should work out on faculty - student ratio so that faculties are able to give good guidance to students $.15 \%$ 'partially agree'that the student faculty needs to be improved as this is creative field.(Fig.8)

\section{Student Faculty Ratio}

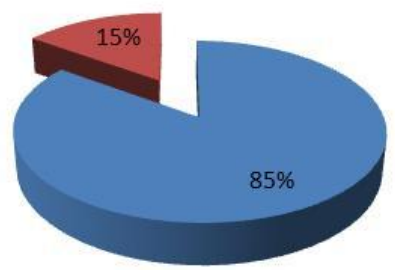

- Fully Agree

a Partailly agree

Fig.8

ix) Faculty workload : 95\%\% respondents agree that the workload of faculties should be reduced so that they are able to do good research and be updated which would reflect in their updated good deliverance .5\% partially ' agree ' (Fig.9)

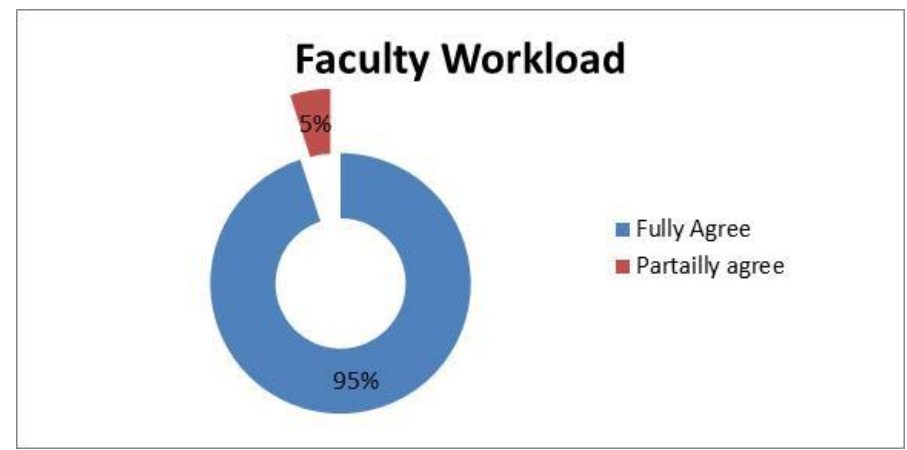

Fig.9 
x) Faculty Exposure and Training: $97 \%$ agree that faculty exposure and training should be emphasized by head of institution by allowing them to attend workshop, seminars and national and international by making provision for monetary support and other assistance as required for upgradation of knowledge so that they can give updated knowledge to the students.

\section{Conclusion}

The Fashion Design Curricula needs to undergo a paradigm shift to accommodate the concept of 'Sustainable Future'. The curriculum needs to be modified with the inclusion of social media, technology and e-communication tools so that the new generation which is Tech savvy and active on social media finds the education easy and interesting to learn. This would give more confidence to both the teacher and the student to understand creative thought which the students express and the teacher to give proper direction to the students thought. Classroom hours needs be decreased so that students get free thinking spaces and exploration time. The assignments should be designed including the concept of sustainability. The Curriculum should give freedom to the students to express their creativity with the utilisation of the Subject Concepts. Institution should ensure that the Teacher - student's ratio is worked out in a manner that the Faculty is able to do research and guide the students in an organised and freeway. The workload on the Teachers also needs to be worked out by institutions so that teacher gets enough time to give to the student query and assistance when required. The International Exchange between various institutes of the world will help students in understanding globalised fashion requirements. Also faculty exchange through special workshop and seminars will help students have multidisciplinary and Trans disciplinary understanding. The interaction between the Faculty -Student needs to be increased through more of mentoring sessions so that there is closer understanding between the teacher and students.

Thus the fashion curricula need to undergo paradigm shift due to society's relationship with design and the requirement of the sustainable future for existence.

\section{References}

Faerm, S. (2012)."Towards a future pedagogy", International Journal of Humanities and Social Science, (2) 23.

Lawale S. and Adams, A.B. (2010)." The decade of education for sustainable development: Towards four pillars of learning", Development 53(4),p547-550.

Kalatinzis.M and Cope.B(2010)."The teacher as designer: pedagogy in the new media age" ,E-learning and digital media, (7), 3 .

Venkatraman, B. (2009).’'Education for sustainable development”,Environment, (51),2.

Wahl,D.C. and Baxter,S.(2008). "Designers role in facilitating sustainable solution". Design issues, (24) 2.

Wilber.A.(2001) .'The theory of everything: An integral vision of business, politics, science and spirituality" Gateway, Dublin. 